\title{
Сейсмогеология Имандровского бассейна - актуальная сводка материалов
}

\author{
Николаева С.Б. ${ }^{1}$, Никонов А.А. ${ }^{2}$
}

${ }^{1}$ Геологический Институт КНЦ РАН, Anamumbl,nikolaeva@geoksc.apatity.ru

${ }^{2}$ Институт физики Земли им. О.Ю. Шмидта РАН, Москва, nikonov@ifz.ru

Аннотация. Представлены результаты детальных палеосейсмогеологических исследований в районе впадины озера Имандра (Кольский регион, северо-восток Фенноскандинавского щита). Изучение палеосейсмодислокаций показало, что в центре Кольского региона установлены следы сильных многократных голоценовых землетрясений. Полученные данные должны учитываться при оценке (переоценке) долговременной сейсмической опасности.

Ключевые слова: палеосейсмодеформации, палеосейсмичность, палеоземлетрясения, озеро Имандра, Кольский регион, Фенноскандинавский щит.

\section{Seismogeology of the Imandra depression - an up-to-date summary of materials}

\author{
Nikolaeva S.B. ${ }^{1}$, Nikonov A.A. ${ }^{2}$ \\ ${ }^{1}$ Geological Institute of Kola Science Center RAS, Apatity,nikolaeva@geoksc.apatity.ru \\ ${ }^{2}$ Schmidt Institute of Physics of the Earth of RAS, Moscow,nikonov@ifz.ru
}

\begin{abstract}
The results of detailed paleoseismological studies in the basin of Lake Imandra (Kola region, northeast of the Fennoscandinavian shield) are presented. The study of paleoseismic dislocations showed that traces of strong multiple Holocene earthquakes were established in the center of the Kola region. The obtained data should be taken into account when assessing (re-evaluating) the long-term seismic hazard.
\end{abstract}

Key words: paleoseismic deformations, paleoseismicity, paleoearthquake, Kola region, Fennoscandian Shield.

\section{Введение}

В последние десятилетия в разных частях Кольского полуострова независимыми группами исследователей обнаружены многочисленные следы древних землетрясений. Результаты этих исследований, однако, до сих пор не учитываются в оценке сейсмической опасности региона в целом и особо ответственных объектов в его границах. Так произошло, в частности, с участком, расположенным в 15 км к северу от площадки Кольской АЭС, где около 20 лет назад были обнаружены палеосейсмодеформации в скальных породах (Николаева, 1993). Полученные новые данные о сейсмопроявлениях как авторов статьи, так и многих других исследователей, дают основу для существенной коррекции оценок сейсмичности в голоцене.

Палеосейсмогеологические исследования были сосредоточены в юго-западной части Кольского региона, в районе озера Имандра в пределах пяти опорных участков (рис. 1). Депрессия озера Имандры, заложенная в кристаллических породах докембрия, представляет собой фрагментированное неотектоническое опускание, генетически сопряженное с Хибинским горным массивом. Блоковый характер котловины определяется сочетанием активизированных разломов субширотного (озера Бабинской и Экостровской Имандр) и субмеридионального (озеро Большая Имандра) простираний.

\section{Результаты исследований}

Участок 1. Западныгй борт Имандровской впадины. Участок расположен в верхней части западного борта впадины оз. Экостровская Имандра, на расстоянии 6 км от ближайшего берега озеpa (рис. 1). К настоящему времени это наиболее подробно изученная очаговая область с фиксацией трех сильных сейсмических событий в прошлом.

Комплексный подход и применение современных специализированных способов изучения внезапных (моментальных) нарушений рельефа позволило выделить здесь структурнотектоническую зону в виде сейсморазрывов, образующих эшелонированную систему отдельных 
сегментов в унаследованной разломной зоне простиранием ССВ $10-25^{\circ}$ и протяженностью более 10 км (Чунский разлом). Активизация разлома происходила с реализацией взбросо-сдвигового механизма, с вертикальной составляющей (поднятым западным крылом) в несколько этапов на протяжении всего поздне- и послеледникового времени. Выделено 3 разновозрастных импульса сейсмических воздействий на участке: юго-восточный с возрастом около 13.5 тыс. л. н., восточный с возрастом 10.3-7.1 тыс. л. н., и северо-восточный - предположительно около 2.5 тыс. л. н. (Николаева и др., 2018). Активизация разлома выразилась в трех землетрясениях силой $\geq 7-8$ баллов, сопровождавшихся сейсмодеформациями разных типов.

Параметры выявленных землетрясений определялась по размерам скальных сейсмодеформаций аналоговым методом и на основе механической модели (Родкин и др., 2012). В последнем случае при этом обычно решалась механическая задача по инерционному смещению скального блока, получившего начальную скорость $\mathrm{V}=\mathrm{PGV}$ движения по субгоризонтальному основанию с трением. Получены следующие пары значений магнитуд (M) в зависимости от расстояния до очага $(\mathrm{R})$ : 1) $\mathrm{M}=6, \mathrm{R} \sim 1$ км, 2) $\mathrm{M}=7, \mathrm{R}=2-5$ км, 3) $\mathrm{M}=8, \mathrm{R}=5-20$ км. Первая пара значений представляется наиболее вероятной. Фиксированная локализация сейсмодеформаций вблизи разрыва указывает, что события имели местный очаг.

Участок 2. Южный борт Имандровской впадины. На юге Имандровской депрессии у западного края оз. Бабинская Имандра, выявлена молодая грабенообразная структура в кристаллических

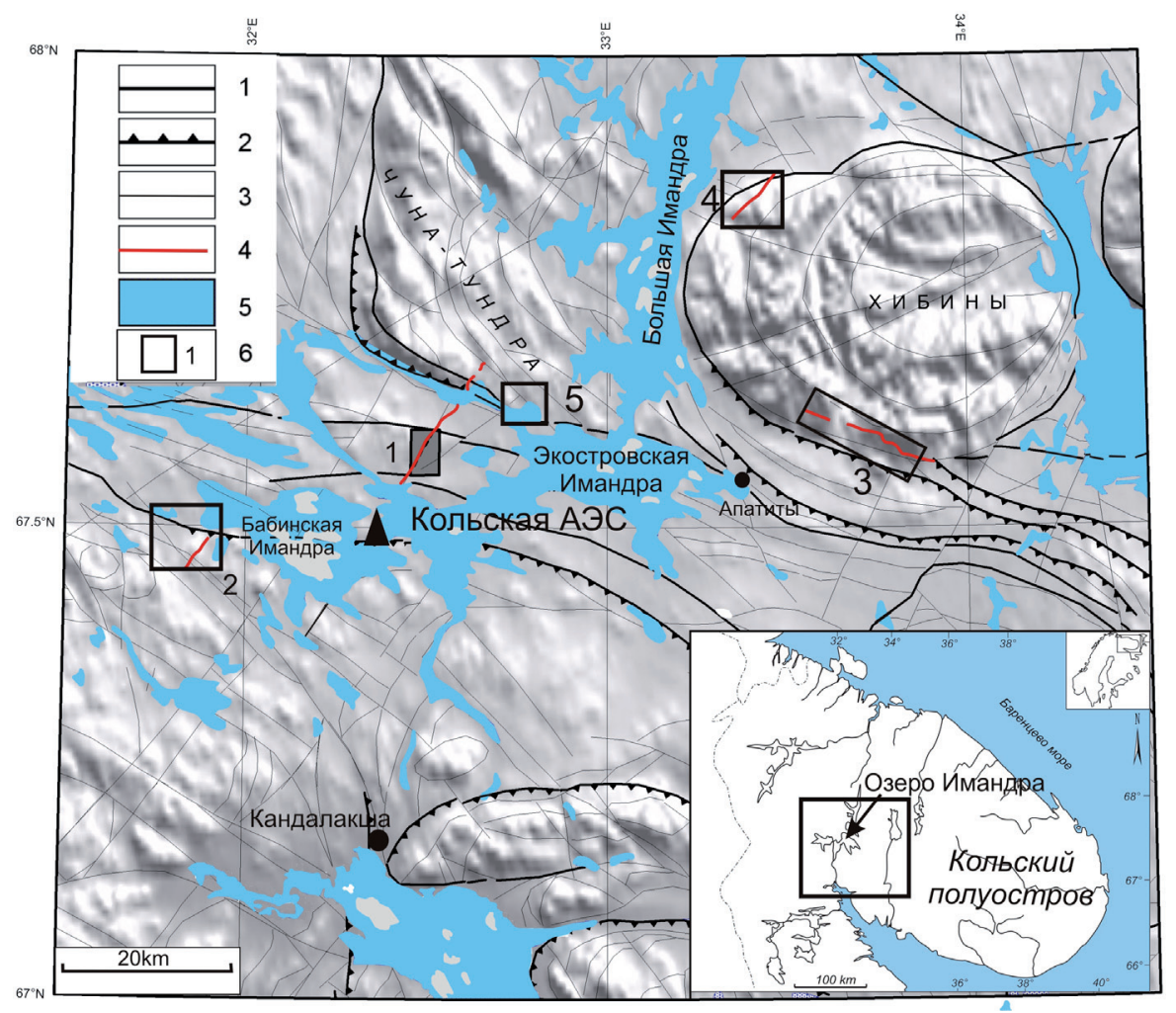

Рис. 1. Карта расположения участков изучения крупных сейсмонарушений (палеоземлетрясений) в районе Имандровской неотектонической впадины по (Николаева и др., 2018), с дополнениями авторов.

Границы геодинамических зон: 1-2 - главные, без определения характеристик - 1, штрихи в сторону падения сместителя - 2; 3 - второстепенные; 4 - разрывные нарушения с признаками активизации в голоцене; 5 - элементы гидрографии; 6 - участки детальных исследований и их номера.

Fig.1. Map of the location of study sites for large seismic dislocations (paleo-earthquakes) of the neotectonic Imandra depression (Nikolaeva et al., 2018), added by the authors.

Boundaries of geodynamic zones: 1-2 - major zones, with unknown parameters (1) and with dipping faults (the dipping direction is shown by hatches) (2); 3 - subordinate zones; 4 - faults segments activated during the postglacial period; 5 - hydrographic structures; 6 - study areas and their numbers. 


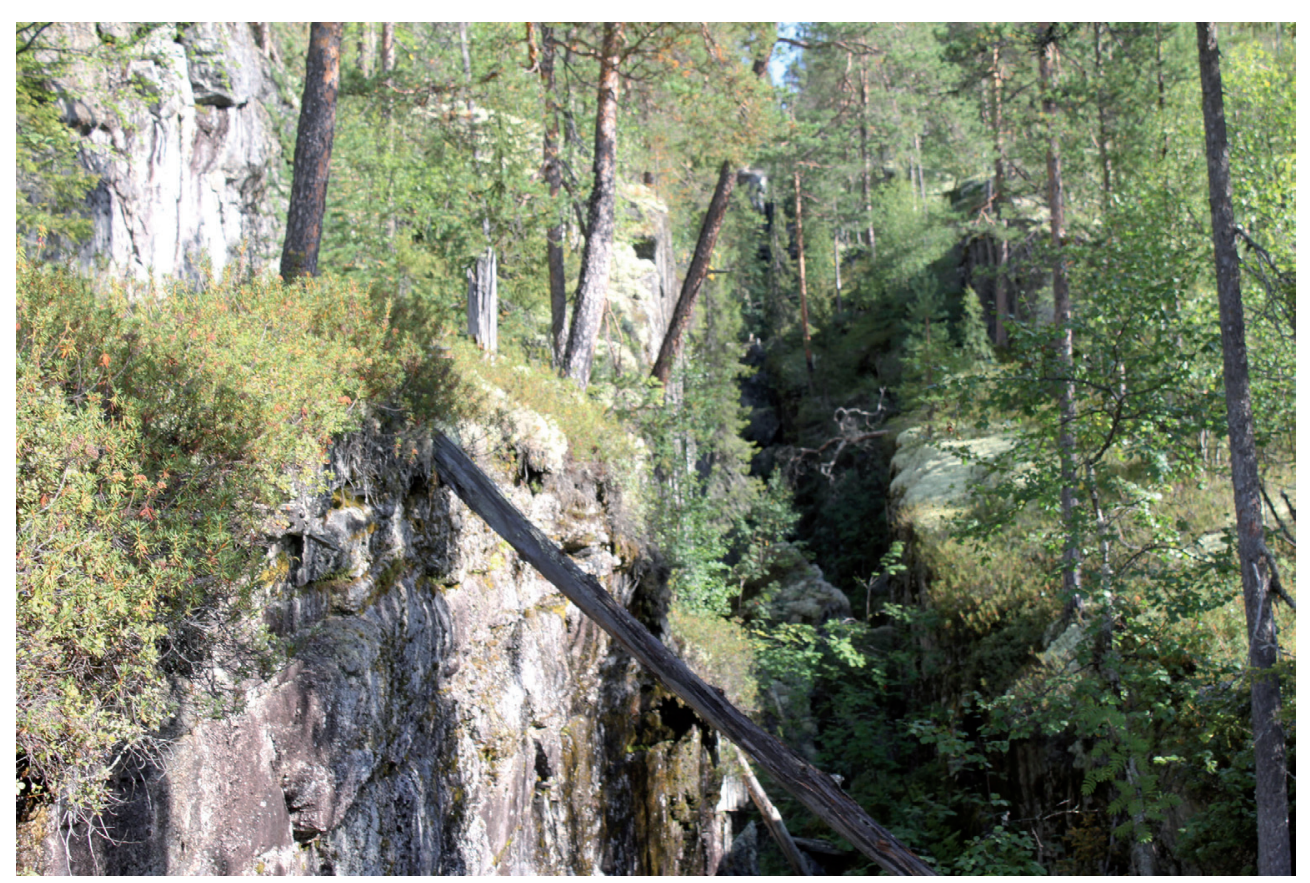

Рис. 2. Сейсмодислокация на южном борту Имандровской депрессии.

Fig. 2. Seismotectonic dislocation on the southern board of the Imandra depression.

породах - «Уполокшский» разлом. Он протягивается в северо-восточном направлении (40-45 $\left.{ }^{\circ}\right)$ на расстояние 7 км, развит в архейских гнейсах и хорошо выражен в рельефе узкими ложбинами и понижениями. Юго-западный фрагмент разлома, представленный микрограбеном, нарушает скальную возвышенность с выс. отм. 330.1 м над у. м., вершина которой частично перекрыта мореной. Микрограбен имеет клиновидную в плане форму, более широкую (до 100 м) в верхней части, которая сужается вниз по склону до узкого зияющего рва, шириной 1.5 м (рис. 2). В верхней части микрограбена наблюдаются многочисленные обвалы и осыпи скального материала. В центральной части глубина микрограбена достигает 30 м. Юго-восточное крыло разрыва опущено и представлено четырьмя сбросовыми уступами в коренных породах. Северо-западное крыло представлено отвесным уступом.

О поздне-послеледниковом подновлении разлома, вероятно неднократном, свидетельствуют отсутствие морены в днище, которое заполнено остороугольным обломочным материалом, свежие осыпи и обвалы, а также нарушение морены поперечными субширотными сбросами (250-270 ${ }^{\circ}$ с с вертикальной амплитудой смещения $-\mathrm{H}_{\text {верт }}=0.6-1.3$ м в верхней части микрограбена (Николаева, 2001).

Комплексные работы по изучению колонок донных отложений малых озер на участке 2 (Николаева и др., 2017) дали возможность значительно уточнить выводы по наземным структурнотектоническим наблюдениям на суше. В скважинах в кернах среди тонкозернистых органогенных отложений обнаружен тонкий прослой песка, а в самой восточной из них - осадочная брекчия за счет экстремального выброса/переноса с берега, определяемые как результат сильного сейсмического воздействия. Согласно радиоуглеродным датам возраст события авторами исследования определен в интервале 6.5-4.7 тыс. лет назад (Николаева и др., 2017). Более аккуратный подсчет позволяет принять время сейсмонарушения $5.8 \pm 0.3$ тыс. лет назад, т.е. средний голоцен. Магнитудный потенциал равен $\mathrm{M}=6.0$.

Участок 3. Восточный борт Имандровской впадины. Хибины, южный склон. Уже на мелкомасштабной карте неотектоники Мурманской области (Атлас..., 1971) среди трех обнаруженных к тому времени в регионе сейсмодислокаций одним был и этот (ныне их многие десятки). В дальнейшем обследование участка осуществляли специалисты (Авенариус, 1989; Николаева, 2003). Сложные, изломанные в плане и профиле контуры щелевого скального нарушения (ущелья) на южном склоне Хибинского массива, как и завалы глыб и обломков в нем, дают основание предполагать, 
что его формирование произошло не одноактно, а в несколько фаз - сейсмотектонических импульсов, интенсивность которых достигала 9 баллов. Происходило это после освобождения ото льда, в голоцене.

Более продвинутые определения осуществлены на том же южном склоне массива, несколько западнее вблизи выхода из гор долины р. Белой, близ ж.д. станции Титан (Романенко и др., 2011). Здесь параллельно долине р. Белой субмеридионально протягивается на 0.8 км ложбина в скальных породах, переходящая на юге в ущелье шириной 100-30 м. По его бортам обнаружены тектонические зоны и следующие им рвы с азимутом простирания CCB- $20^{\circ}$, как и само ущелье и вся ложбина. Тектоническая предопределенность морфоструктуры, следовательно, сомнений не вызывает. Ложбина имеет новейший возраст, но в ущелье имеются явные признаки сейсмотектонических воздействий в голоцене, в первую очередь, в виде скальных обвалов с бортов, с подпруживанием боковой речки. Авторы исследования обоснованно принимают здесь возникновение землетрясения I=8-9 баллов. Его возраст по дате внезапного подпруживания ложбины определен $5.75 \pm 0.15$ тыс. лет назад. С учетом позиции датированного образца на 10 см выше подошвы озерно-подпрудных отложений возраст сейсмического события определяется $6.0 \pm 0.2$ тыс. лет назад. Магнитудный потенциал равен $\mathrm{M}=6.0$.

Участок 4. Восточный борт Имандровской впадины. Хибины, западный склон. Аку-Аку. Это ущелье на западном склоне Хибинского массива в его С3 части, известное под названием «АкуАку», оно обследовано летом 2018 г. М.В. Родкиным и А.О. Королевой. Ущелье ССВ простирания $\left(20^{\circ}\right)$, общей длиной 5-6 км рассекает наискосок нижнюю часть обращенного к Имандровской впадине склона Хибинского горного массива. Дно его расположено на высоте около 300 м над уровнем оз. Имандра. Молодые смещения по разрывам фиксируются по обеим стенкам ущелья на высоте 2-6 м над современным дном в виде свежих скальных субвертикальных плоскостей и системы блоково-глыбовых обвалов. Помимо вертикальных смещений в пределах первых метров обнаружены и горизонтальные продольно-сдвиговые на величину 0.15-0.35 м. По ряду признаков, как в нижней части ущелья, на большей части его протяжения, так и на плоских, обработанных ледником пологих скальных выходах наверху, определяются сейсмонарушения (сейсмодеформации) в виде двух возрастных генераций. Пока они оцениваются, как относящиеся к среднему и позднему голоцену. Сила воздействия в этой очаговой области $-\geq 8$ баллов. На том же западном склоне Хибинского массива, но южнее, имеются и другие, отдельные участки разрывных сейсмодислокаций, подлежащие специальному изучению.

Участок 5. Воче-Ламбина. Участок расположен в северо-западной части бассейна оз. Экостровская Имандра. Здесь были обследованы разрывные нарушения в виде оврагообразных ложбин, логов и трещин-ущелий, аналогичных вышеприведенным, но значительно меньших масштабов. Все они имеют признаки сейсмогенности. Характерной особенностью ряда ущелий является отсутствие на их склонах и в днищах следов водно-ледниковой деятельности, что может свидетельствовать об их послеледниковом образовании или подновлении зон древних разломов.

\section{Обсуждение результатов и выводы}

Впервые осуществленное обобщение опубликованных разными авторами в последние десятилетия и новых материалов о сильных землетрясениях прошлого заставляет кардинально менять существующие оценки сейсмической опасности в масштабе тысячелетий в районе среднекольского кластера, признавая здесь реальными в прошлом и вероятные в будущем события интенсивностью не 5 баллов в эпицентральных зонах, как принималось, а 8-9 баллов. К настоящему времени определено, что только в голоцене, не считая позднеледниковья, в Имандровской впадине со всех ее сторон, кроме севера, где ситуация недостаточно выяснена, располагаются очаги разрушительных землетрясений. Всего пока в интервале 8-2 тыс. лет таких событий выявлено, как минимум, 6. Отсюда возможна оценка средней повторяемости в послеледниковое время.

Обращает внимание сходство разломных, сейсмотектонических структур по бортам Имандровской впадины и на южном склоне Хибинского массива, на всех участках, по простиранию к 
$\mathrm{CCB}$, в морфотектоническом, в кинематическом отношениях. Это ущелья вдоль активизированных в голоцене разломов, простирающиеся по азимуту $15-20^{\circ}$ северные и $30-40{ }^{\circ}$ - южное, с признаками воздымания западных крыльев и с правосдвиговой составляющей. По-видимому, весь район в послеледниковое время как рамповая структура находится в условиях общего субширотного сжатия с разрядкой напряжений в виде редких мощных землетрясений.

Механизм очага сильных землетрясений прошлого на некоторых рассматриваемых участках, насколько можно судить по доступным морфотектоническим данным, сходен, это в основном взбросо-сдвиги и сбросы. Величины подвижек у поверхности, в скальном субстрате, при каждом событии, оцениваются первыми метрами по вертикали и первыми десятками см - по горизонтали.

Проведенные детальные сейсмотектонические, палеосейсмогеологические и геофизические исследования показали, что в центре Кольского региона, по современным оценкам, установлены следы сильных многократных голоценовых высокомагнитудных землетрясений, что должно учитываться при оценке (переоценке) долговременной сейсмической опасности особенно на участках с объектами особой ответственности, например, Кольской АЭС.

Исследования проведены в рамках темы НИР ГИ КНЦ РАН № 0226-2019-0054.

\section{Литература}

1. Авенариус И.Г. Морфоструктурный анализ зоны новейших дислокаций на южном склоне Хибин // Геоморфология. 1989. № 2. С. 52-56.

2. Атлас Мурманской области. М. Главное управление геодезии и картографии при совете министров СССР. 1971.

3. Николаева С.Б. Палеосейсмодислокации южной части Кольского полуострова // Четвертичные отложения и новейшая тектоника ледниковых областей Восточной Европы. Апатиты: Изд-во: КНЦ РАН. 1993. С. 69-81.

4. Николаева С.Б. Палеосейсмологические проявления в СВ части Балтийского щита и их геологотектоническая позиция // Геоморфология. 2001. № 4. С. 66-74.

5. Николаева С.Б. Палеосейсмодислокации в Хибинском массиве (северо-восточная часть Балтийского щита, Кольский полуостров) / Напряженно-деформированное состояние и сейсмичность литосферы. Тр. Всеросс. совещ. Новосибирск. 2003. С. 409-412.

6. Николаева С.Б., Лаврова Н.Б., Денисов Д.Б. Катастрофическое событие голоцена в донных осадках озер Кольского полуострова (СВ Фенноскандинавского щита) // ДАН. 2017. Т. 473. № 1. С. 88-92.

7. Николаева С.Б., Никонов А.А., Шварев С.В., Родкин М.В. Детальные палеосейсмогеологические исследования в бортовой зоне впадины озера Имандра (Кольский регион): новые подходы и результаты // Геология и геофизика. 2018. Т. 59. № 6. С. 866-880.

8. Родкин М.В., Никонов А.А., Шварев С.В. Оценка величин сейсмических воздействий по нарушениям и смещениям в скальных массивах // Геодинамика и тектонофизика. 2012. Вып. 3. С. 203-237.

9. Романенко Ф.А., Лукашов А.А., Шилова О.С. Катастрофические гравитационные процессы на Севере России и опыт их радиоуглеродного датирования //Геоморфология. 2011. № 3. С. 87-94. 